\title{
Weight Gain and De Novo Metabolic Disorders after Liver Transplantation
}

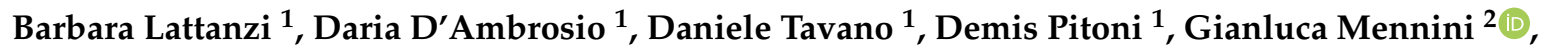 \\ Stefano Ginanni Corradini ${ }^{1}$, Massimo Rossi ${ }^{2}$ and Manuela Merli ${ }^{1, *(D)}$ \\ 1 Department of Translational and Precision medicine, Sapienza University of Rome, Italy Viale \\ dell’Università 37, 00185 Roma, Italy; lattanzi.b@gmail.com (B.L.); daria.dambrosio@uniroma1.it (D.D.); \\ daniele.tavano@uniroma1.it (D.T.); pitonidemis@gmail.com (D.P.); stefano.corradini@uniroma1.it (S.G.C.) \\ 2 Department of General Surgery "Paride Stefanini", Liver Transplantation Unit, "Sapienza" University, \\ 00185 Rome, Italy; gianluca.mennini@uniroma1.it (G.M.); massimo.rossi@uniroma1.it (M.R.) \\ * Correspondence: Manuela.merli@uniroma1.it; Tel.: +39-06-4997-2001
}

Received: 11 November 2019; Accepted: 5 December 2019; Published: 10 December 2019

check for

\begin{abstract}
The development of nutritional and metabolic abnormalities represents an important burden in patients after liver transplantation (LT). Our study aimed at evaluating the incidence, time of onset, and risk factors for nutritional and metabolic abnormalities in patients after LT. The study was a single-center retrospective study. Consecutive patients undergoing elective LT from 2000 to 2016 were enrolled. The presence of at least two among arterial hypertension (AH), diabetes mellitus (DM), dyslipidemia, and obesity (BMI $\geq 30 \mathrm{Kg} / \mathrm{m}^{2}$ ) was utilized to define patients with the metabolic disorder (MD). Three hundred and fifteen patients were enrolled; the median age was 56 years (68\% males). Non-alcoholic steatohepatitis (NASH) was the origin of liver disease in 10\% of patients. During follow-up, 39\% of patients developed $\mathrm{AH}, 18 \% \mathrm{DM}$, and $17 \%$ dyslipidemia. Metabolic disorders were observed in $32 \%$ of patients. The NASH etiology (OR: 6.2; CI 95\% 0.5-3; $p=0.003$ ) and a longer follow-up (OR: 1.2; CI 95\% 0.004-0.02; $p=0.002$ ) were associated with de novo MD. In conclusion, nutritional and metabolic disorders are a frequent complication after LT, being present in up to one-third of patients. The NASH etiology and a longer distance from LT are associated with de novo MD after LT.
\end{abstract}

Keywords: liver transplantation (LT); body mass index (BMI); metabolic disorders (MDs), non-alcoholic steatohepatitis (NASH)

\section{Introduction}

The development of nutritional and metabolic abnormalities represents an important burden in patients after liver transplantation (LT) [1]. Immunosuppressive therapy, sedentary lifestyle, increase in appetite, and changes in eating habits are all contributing factors.

After, LT patients may become overweight and even morbidly obese [1,2]. More recently, non-alcoholic steatohepatitis (NASH) is increasing as a cause of liver disease which may lead to liver cirrhosis and end-stage liver disease. Non-alcoholic steatohepatitis is the most rapidly rising indication for LT in the United States, and it is projected to become the most common indication in future years $[3,4]$. Patients with a diagnosis of NASH are frequently overweight or obese $[5,6]$, and nutritional and metabolic disorders have been found to persist or rapidly recur after LT [7-9].

The chronic use of immunosuppressants, particularly corticosteroids and calcineurin inhibitors, may also contribute to worsen metabolic disorders and to weight gain [2]. Indeed, corticosteroids promote insulin resistance through downregulation of insulin production, upregulation of hepatic gluconeogenesis, and a decrease in glucose utilization in peripheral tissues $[10,11]$. Calcineurin 
inhibitors (CNIs), tacrolimus, and cyclosporine are known to increase vasoconstriction and cause sodium-dependent volume expansion leading to arterial hypertension [12]. Calcineurin inhibitors have also been associated with decreased insulin sensitivity and reduced insulin release [13]. Moreover, both CNIs and mammalian target of rapamycin (mTOR) inhibitors (sirolimus and everolimus) increase serum lipid levels, the latter affecting the levels more severely [14].

An increase in body weight, arterial hypertension, and serum glucose levels at 6 months have been reported as predictors of metabolic syndrome after LT [15]. Furthermore, metabolic disorders may also favor cardiovascular diseases, increasing cardiovascular mortality in the long term after LT [16].

In this setting, patients with metabolic disorder after LT constitute a high-risk group in which therapeutic interventions should be optimized $[9,17]$.

Our study aimed at evaluating the incidence, time of onset, and risk factors for nutritional disorders and de novo metabolic abnormalities in patients after LT.

\section{Materials and Methods}

The study was a single-center retrospective study. The medical records of all patients undergoing elective LT at the University Hospital Policlinico Umberto I in Rome from 2000 to 2016 were reviewed. Exclusion criteria were age $<18$ years, re-transplant, combined kidney-liver transplant, and a follow-up $\leq 3$ months. All patients were followed from the date of transplantation until death, loss to follow-up or end of study (15 June 2019). Age, gender, body mass index, liver disease etiology, immunosuppressive treatment (at discharge and maintenance), and time of corticosteroid therapy were collected in each patient. Body mass index (BMI), diagnosis of diabetes mellitus (DM), arterial hypertension (AH), and dyslipidemia were derived from clinical records before LT and at 1, 3, 5, and 10 years after LT. Body weight before liver transplant was always corrected for water retention. Metabolic disorders were defined as de novo when they appeared after LT. The presence of at least two among AH, DM, dyslipidemia, and $\mathrm{BMI} \geq 30 \mathrm{Kg} / \mathrm{m}^{2}$ during follow-up was arbitrarily utilized to define patients as those with metabolic disorder (MD).

All patients were followed at the outpatient clinic of the Transplant Centre of our University Hospital. The first-line standard immunosuppressive therapy was triple therapy with steroids, CNIs, and mycophenolate mofetil (MMF); steroids were generally continued for 3-6 months and MMF for 1 year. In the case of autoimmune etiology, the steroid therapy was maintained chronically at low doses; in the case of kidney dysfunction, MMF was continued or reintroduced together with CNIs to maintain the lowest dose of CNIs. Everolimus (EVR) was also alternatively utilized to discontinue CNIs completely in patients with kidney dysfunction.

Results are expressed as the mean \pm standard deviation, median, and range or as percentage as indicated. For the comparison among groups, the Pearson chi square test or the Fischer exact test were used for categorical variables. For continuous variables, the Mann-Whitney test was applied. A multivariate logistic regression analysis was utilized to identify factors independently associated with the development of metabolic disorders after LT. Only variables with a $p$-value $<0.05$ at univariate analysis were included.

The paired " $t$ " test was utilized for the analysis of repeated variables. Values of $p<0.05$ were considered statistically significant.

\section{Results}

\subsection{Study Population}

A total of 315 patients submitted to liver transplantation were enrolled in the study (Figure 1), the median age was 56 years (range 18-68), 68\% were males, and the most frequent origin of LT was the hepatitis $\mathrm{C}$ virus, followed by alcohol abuse. Thirty-one patients $(10 \%)$ were transplanted for NASH. Before $\mathrm{LT}, 18 \%$ of patients presented $\mathrm{AH}, 28 \% \mathrm{DM}$, and $12 \%$ dyslipidemia; a BMI $\geq 30$ was present in $14 \%$ of patients. Seventeen percent of patients had at least two metabolic disorders. Demographic and clinical characteristics of patients at transplant are shown in Table 1. 


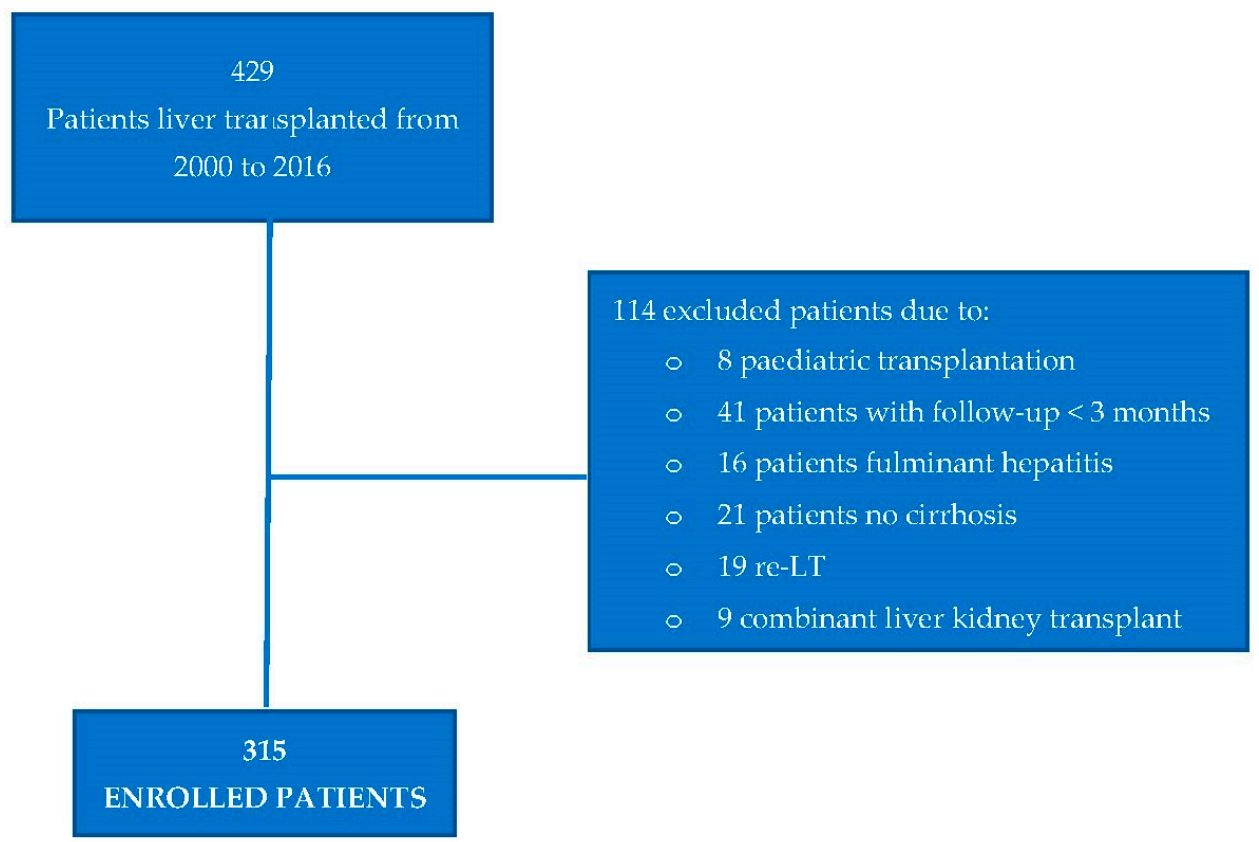

Figure 1. Flowchart of the study.

Table 1. Demographic and clinical characteristics of the 315 patients at the time of liver transplantation (LT).

\begin{tabular}{|c|c|}
\hline Variable & $\begin{array}{l}\text { Patients }(n= \\
315)\end{array}$ \\
\hline Age at LT (years) & $56(18-68)$ \\
\hline MELD score & $15(6-40)$ \\
\hline $\operatorname{BMI}\left(\mathrm{Kg} / \mathrm{m}^{2}\right) *$ & $25.3(17-38)$ \\
\hline $\mathrm{BMI} \geq 25, n(\%) *$ & $138(44 \%)$ \\
\hline $\mathrm{BMI} \geq 30, n(\%) *$ & $44(14 \%)$ \\
\hline Male gender, $n(\%)$ & $209(68 \%)$ \\
\hline \multicolumn{2}{|l|}{ Etiology, $n(\%)$} \\
\hline $\mathrm{HCV}$ & $118(37 \%)$ \\
\hline $\mathrm{HBV}$ & $54(17 \%)$ \\
\hline NASH & $31(10 \%)$ \\
\hline Alcohol & $67(21 \%)$ \\
\hline Other & $45(15 \%)$ \\
\hline $\mathrm{HCC}, n(\%)$ & $141(45 \%)$ \\
\hline AH pre-LT, $n(\%)$ & $58(18 \%)$ \\
\hline DM pre-LT, $n(\%)$ & $86(28 \%)$ \\
\hline Dyslipidemia pre-LT, $n(\%)$ & $33(12 \%)$ \\
\hline At least two metabolic disorders (MD), $n(\%)$ & $54(17 \%)$ \\
\hline \multicolumn{2}{|l|}{ Immunosuppressive treatment at discharge, $n(\%)$} \\
\hline Triple therapy with TAC (steroids + MMF + TAC) & $259(82 \%)$ \\
\hline Triple therapy with EVR (steroids + MMF + EVR) & $7(2 \%)$ \\
\hline Dual therapy with TAC (steroids + TAC) & $45(15 \%)$ \\
\hline Other & $4(1 \%)$ \\
\hline Duration of steroids treatment (months) & $6.5(0-125)$ \\
\hline Follow-up (months) & $75.5(3-220)$ \\
\hline
\end{tabular}

Continuous variables expressed as median (range). Abbreviations: LT-liver transplantation; HCC-hepatocellular carcinoma; BMI—body mass index; MELD—model for end-stage liver disease; HCV—hepatitis C virus; HBV—hepatitis B virus; NASH — non-alcoholic steatohepatitis; AH—arterial hypertension; DM — diabetes mellitus; MMF—-mycophenolate mofetil; TAC—-tacrolimus; EVR—everolimus. * BMI refers to body weight corrected for water retention. 


\subsection{Weight Gain After LT}

Figure 2 shows the trend of BMI after LT. Mean BMI was slightly but significantly decreased 1 year after LT ( $25.8 \pm 4$ versus $24.5 \pm 5 \mathrm{Kg} / \mathrm{m}^{2}, p=0.03$; basal versus 1 year, respectively). Later on, BMI tended to gradually increase and became significantly higher versus pre-transplant levels in the third year $\left(24.5 \pm 5\right.$ versus $26.2 \pm 4 \mathrm{Kg} / \mathrm{m}^{2}, p=0.04$ basal versus 3 years, respectively), reaching a plateau at 5 and 10 years of follow-up. Patients transplanted for NASH showed a different pattern: BMI was unchanged at 1 year in comparison to pre-LT condition $\left(27 \pm 3\right.$ versus $26.8 \pm 4 \mathrm{Kg} / \mathrm{m}^{2} ; p=0.6$, basal versus 1 year, respectively), while it increased progressively at $3\left(28.4 \pm 5 \mathrm{Kg} / \mathrm{m}^{2}, p=0.05\right.$ versus basal) and 5 years $\left(28.8 \pm 4 \mathrm{Kg} / \mathrm{m}^{2}, p=0.05\right.$ versus basal) (Figure 2).

\section{Trend of BMI during FU}

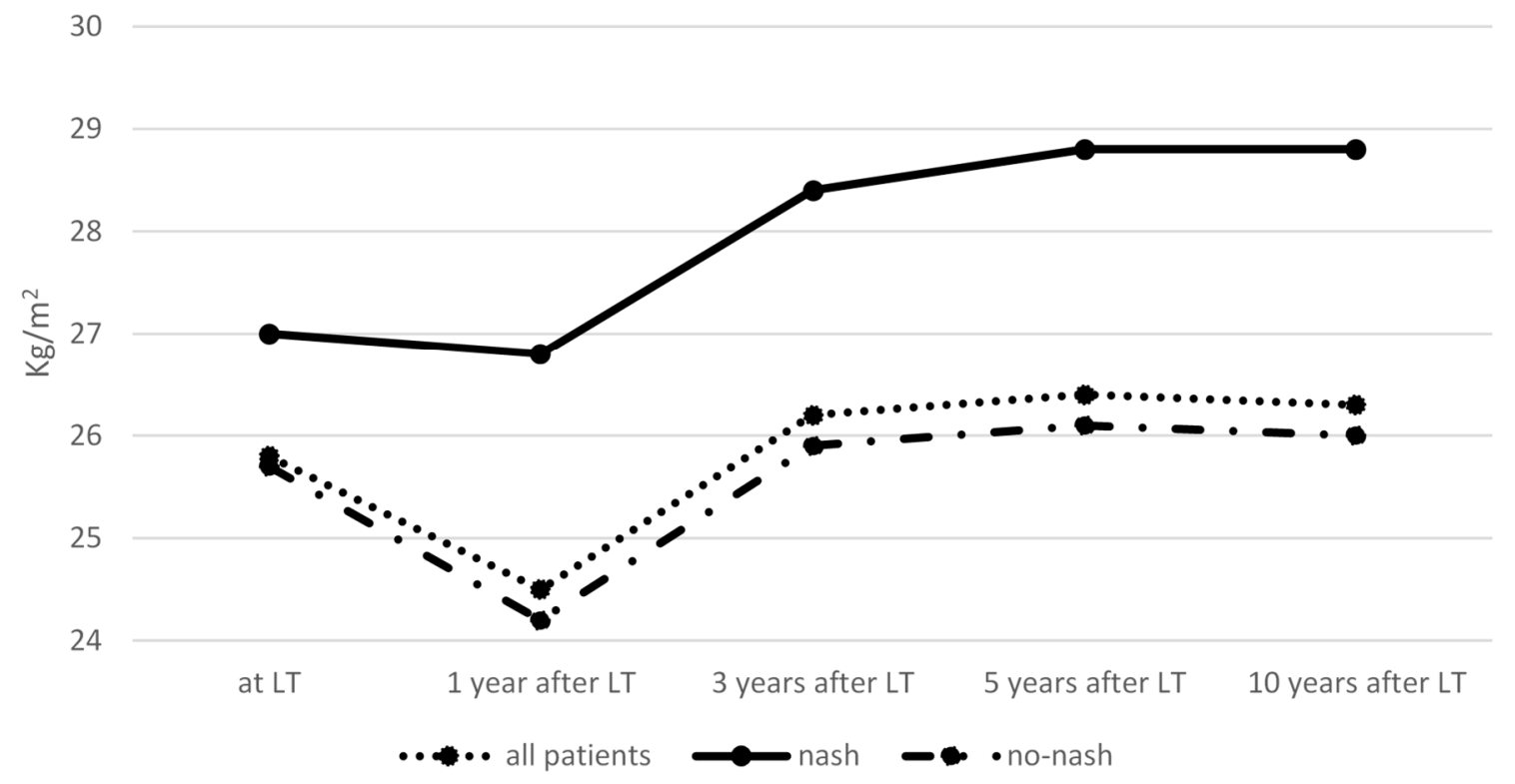

Figure 2. BMI modifications in 315 subjects followed after liver transplantation. All patients (dotted line), patients with previous NASH (continue line), patients with no-NASH (dashed-dotted line). * $<0.05$ compared to BMI at LT.

\subsection{Metabolic Disorders After LT}

During a median follow-up of 75.5 months (range 3-220 months), 122 patients (39\%) developed de novo AH after LT. Fifty percent of de novo AH was diagnosed within the first year after LT. De novo DM was diagnosed in 57 patients (18\%) during the follow-up. Fifty-nine percent of patients developed this diagnosis within the first year after LT. De novo dyslipidemia was diagnosed in 53 patients (17\%), $39 \%$ of them developed this disorder within the first year after surgery (Figure 3).

At least two de novo metabolic disorders were reported in $32 \%$ of overall patients; of this, $42 \%$ were diagnosed during the first year, $67 \%$ within the third year after LT, and $82 \%$ within the 5 th year. Patients transplanted for NASH showed the highest rate of de novo DM, HA, and MD (Table 2). 

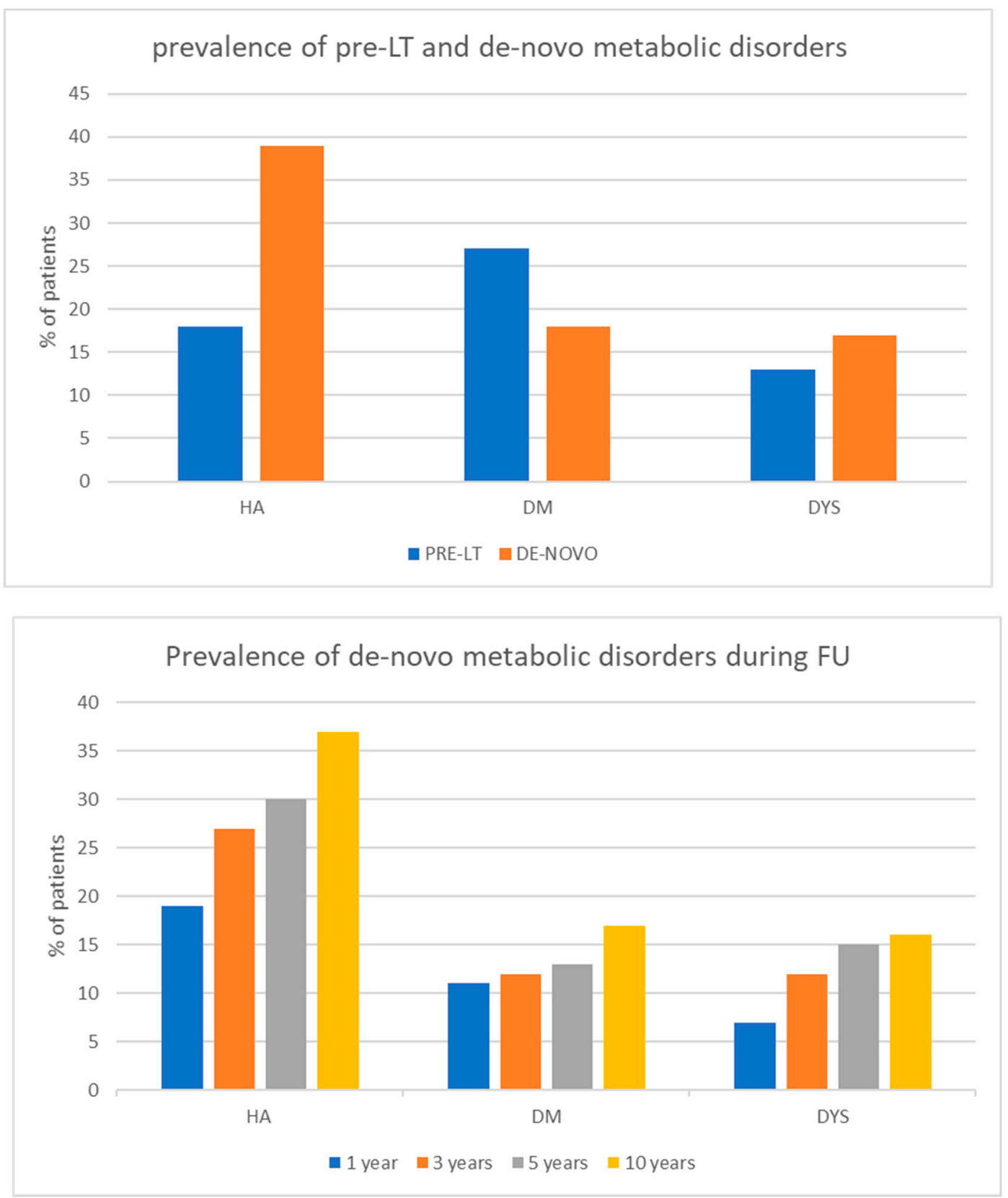

Figure 3. Prevalence and time of onset of de novo metabolic disorders after LT.

Table 2. Incidence of metabolic disorders before and after liver transplantation in patients transplanted or not for non-alcoholic steatohepatitis.

\begin{tabular}{cccc}
\hline Variable & $\begin{array}{c}\text { Transplanted for NASH } \\
\text { 31 Patients }\end{array}$ & $\begin{array}{c}\text { Transplanted for Other } \\
\text { Etiology 294 Patients }\end{array}$ & $p$-Value \\
\hline De novo DM & $\mathbf{1 0 ( 3 2 \% )}$ & $\mathbf{4 7}(\mathbf{1 6 \% )}$ & $\mathbf{0 . 0 3}$ \\
De novo AH & $\mathbf{2 0 ( 6 4 \% )}$ & $\mathbf{1 0 2}(\mathbf{3 4} \%)$ & $\mathbf{0 . 0 0 7}$ \\
De novo Dyslipidemia & $7(23 \%)$ & $46(14 \%)$ & 0.5 \\
De novo MD & $\mathbf{1 7}(\mathbf{5 5 \% )}$ & $\mathbf{8 5}(\mathbf{2 8} \%)$ & $\mathbf{0 . 0 0 3}$ \\
Pre-LT DM & $8(26 \%)$ & $78(26 \%)$ & 0.89 \\
Pre-LT AH & $5(16 \%)$ & $53(18 \%)$ & 0.7 \\
Pre-LT Dyslipidemia & $\mathbf{1 6 ( 5 1 \% )}$ & $\mathbf{1 7}(\mathbf{6} \%)$ & $<\mathbf{0 . 0 0 0 1}$ \\
Pre-LT MD & $\mathbf{1 4}(\mathbf{4 5 \% )}$ & $\mathbf{3 6}(\mathbf{1 2} \%)$ & $<\mathbf{0 . 0 0 0 1}$ \\
\hline
\end{tabular}

Abbreviations: NASH—non-alcoholic steatohepatitis; DM—diabetes mellitus; AH—arterial hypertension; LT—liver transplantation; MD—metabolic disorder. The statistically significant data are in bold. 


\subsection{Risk Factors Associated with De Novo Metabolic Disorders}

The univariate analysis identified NASH, time of follow-up after LT, a higher BMI before and at 1 year from LT as risk factors for de novo MD. The use of tacrolimus seemed to be protective for the development of MD (Table 3). The multivariate analysis selected NASH etiology (OR: 6.2; CI 95\% $0.5-3 ; p=0.003$ ) and a longer FU (OR: 1.2 ; CI 95\% 0.004-0.02; $p=0.002)$ as the only independent risk factors associated with the development of de novo MD.

Table 3. Univariate analysis for the development of metabolic disorder status after liver transplant.

\begin{tabular}{|c|c|c|c|}
\hline Variable & De Novo MD 102 & Non-De Novo MD 213 & $p$-Value \\
\hline Male gender, n (\%) & $73(72 \%)$ & $136(64 \%)$ & 0.2 \\
\hline Age (years) & $54 \pm 8$ & $54 \pm 11$ & 0.9 \\
\hline Etiology NASH, n (\%) & $26(25 \%)$ & $5(3 \%)$ & $<0.0001$ \\
\hline BMI pre-LT $\left(\mathrm{kg} / \mathrm{m}^{2}\right)$ & $26.9 \pm 3$ & $25.6 \pm 4$ & 0.01 \\
\hline BMI 1 year after LT $\left(\mathrm{kg} / \mathrm{m}^{2}\right)$ & $26.4 \pm 5$ & $24 \pm 4$ & 0.02 \\
\hline MELD & $14 \pm 5$ & $16 \pm 7$ & 0.1 \\
\hline \multicolumn{4}{|l|}{ Immunosuppressive drugs at discharge } \\
\hline Steroids & $98(96 \%)$ & $200(94 \%)$ & 0.2 \\
\hline MMF & $87(85 \%)$ & $176(83 \%)$ & 0.6 \\
\hline AZA & $14(14 \%)$ & $21(10 \%)$ & 0.3 \\
\hline Tacrolimus & $77(76 \%)$ & $191(90 \%)$ & 0.01 \\
\hline Everolimus & $20(2 \%)$ & $42(2 \%)$ & 0.9 \\
\hline Cyclosporine & $24(24 \%)$ & $27(13 \%)$ & 0.09 \\
\hline \multicolumn{4}{|c|}{ Immunosuppressive treatment at discharge } \\
\hline $\begin{array}{l}\text { Triple therapy (steroids + MMF + } \\
\text { TAC/EVR) }\end{array}$ & $92(90 \%)$ & $179(84 \%)$ & \multirow[t]{2}{*}{0.3} \\
\hline Dual therapy (steroids + TAC) & $11(10 \%)$ & $34(16 \%)$ & \\
\hline \multicolumn{4}{|c|}{ Immunosuppressive drugs as maintenance } \\
\hline Steroids & $4(4 \%)$ & $35(17 \%)$ & 0.02 \\
\hline MMF & $27(26 \%)$ & $53(25 \%)$ & 0.9 \\
\hline AZA & $8(8 \%)$ & $6(3 \%)$ & 0.3 \\
\hline Tacrolimus & $65(64 \%)$ & $176(83 \%)$ & 0.007 \\
\hline Everolimus & $19(19 \%)$ & $234(11 \%)$ & 0.2 \\
\hline Cyclosporine & $20(20 \%)$ & $27(13 \%)$ & 0.2 \\
\hline \multicolumn{4}{|c|}{ Immunosuppressive maintenance treatment } \\
\hline $\begin{array}{l}\text { Triple Therapy (steroids + MMF + } \\
\text { TAC/EVR) }\end{array}$ & 0 & $19(9 \%)$ & 0.03 \\
\hline Dual Therapy (steroids + TAC) & $32(32 \%)$ & $61(29 \%)$ & 0.6 \\
\hline Monotherapy (TAC/EVR) & $67(66 \%)$ & $142(67 \%)$ & 0.7 \\
\hline Time of steroid therapy & $10 \pm 9$ & $12 \pm 16$ & 0.4 \\
\hline FU months & $114 \pm 48$ & $86 \pm 56$ & 0.001 \\
\hline
\end{tabular}

Abbreviations: LT—liver transplantation; BMI—body mass index; MELD—model for end-stage liver disease; NASH—non-alcoholic steatohepatitis; MMF—mycophenolate mofetil; TAC—tacrolimus; EVR-everolimus; MDs-metabolic disorders. The statistically significant data are in bold.

\section{Discussion}

Metabolic disorders and weight gain are important burdens in patients after LT. These are due to the fact of multiple reasons such as a sedentary lifestyle, increased appetite, and modifications in eating habits [1]. The chronic use of immunosuppressants may also play a role in the development of these conditions [2].

Weight gain after liver transplantation is welcome in patients transplanted with severe nutritional depletion; however, a rapid weight gain might be harmful. In our population, mean BMI at the time of LT was only slightly above normal values; however, these patients were likely overhydrated during end-stage liver disease; therefore, BMI was possibly overestimated. The majority of our patients were 
therefore normal or undernourished at transplantation. Mean BMI, in our series, showed a trend to decrease the first year after surgery and tended to recover later on. This result is at variance with studies showing a rapid and severe weight gain after liver transplantation $[9,18,19]$. This difference might depend on a lower prevalence of patients with NASH origin in our study (only 10\%). Indeed, in the previously cited studies, the percentage of patients transplanted for NASH was much greater. In the 31 NASH patients in our series, we observed that BMI progressively increased from the first year after surgery was significantly higher at 3 and 5 years. A higher percentage of patients transplanted for NASH is therefore likely to modify the pattern of weight changes after LT throughout a more frequent development of post-transplant obesity. In this regard, bariatric surgery has been proposed before or concomitant to LT in patients with morbid obesity [20].

In our study, we found a high rate of de novo metabolic disorders (AH, DM, dyslipidemia) after LT. Our finding is in keeping with what has been previously reported [1,19,21]; however, most of the former studies did not focus on de novo metabolic disorders as in the present investigation.

The majority of de novo disorders developed, in our study, in the first year after LT. In the subgroup of patients transplanted for NASH, de novo AH, DM, and MD occurred even at a higher rate.

It has been suggested that immunosuppressive strategies (the kind of immunosuppressant, the dosages, and the period length of steroid assumption) may play a role in the rate of development of de novo AH, DM, dyslipidemia, and MD, after LT [22]. In our study, we failed to find a correlation with $\mathrm{MD}$ and the different immunosuppressive regimens adopted. Tacrolimus appeared to have a protective role in the onset of de novo MD at univariate analysis but was not found to be an independent predictor at multivariate analysis. The retrospective nature of our study has certainly limited the possibility to follow all the dose modifications of the immunosuppressive therapy which is frequently tailored in the individual patients according to nephrotoxicity, rejection risk or clinical events.

The onset of de novo metabolic disorders after LT, not surprisingly, was associated with $\mathrm{NASH}$ as the origin of the previous liver disease and increased during the time. A longer distance from transplantation is likely to identify those patients with the longest time of exposure to immunosuppressants and those with older age. Previous studies reported a similar association among older age and obesity, AH, DM, and metabolic syndrome after LT [23-25].

Our study has some limitations, being a monocentric and retrospective study. The retrospective analysis of our database prevented the possibility to diagnose a metabolic syndrome according to the proposed cut-offs as HDL cholesterol and the abdominal circumference were not reported in the database. For this reason, we utilized the term "metabolic disorders" to represent the development of relevant metabolic disorders (at least two among AH, DM, dyslipidemia, and obesity) in our patients.

\section{Conclusions}

In conclusion, de novo HA, DM, dyslipidemia, and obesity are frequent in liver transplant patients, mostly in those with NASH etiology. These latter patients also experience a progressive weight gain which contributes to metabolic disorders. Interventions to minimize the risk of developing weight gain and metabolic disorders after LT need to be planned. Giving particular care to those patients at higher risk.

Author Contributions: B.L. and D.D., study concept and design acquisition of data, analysis and interpretation of data, manuscript preparation; D.P. and D.T., acquisition of data; M.M., study concept and design, analysis and interpretation of data; manuscript preparation; final drafting of the manuscript; G.M., S.G.C. and M.R., manuscript supervision.

Funding: This research was funded by the Universita' degli Studi di Roma Sapienza prot. C26A10TCSL.

Conflicts of Interest: The authors declare no conflict of interest. 


\section{References}

1. Iadevaia, M.; Giusto, M.; Giannelli, V.; Lai, Q.; Rossi, M.; Berloco, P.; Corradinia, G.; Merli, M. Metabolic syndrome and cardiovascular risk after liver transplantation: A single-center experience. Transpl. Proc. 2012, 44, 2005-2006. [CrossRef] [PubMed]

2. Duchini, A.; Brunson, M.E. Roux-en-Y gastric bypass for recurrent nonalcoholic steatohepatitis in liver transplant recipients with morbid obesity. Transplantation 2001, 72, 156-159. [CrossRef] [PubMed]

3. Wawrzynowicz-Syczewska, M.; Karpinska, E.; Jurczyk, K.; Laurans, L.; Boron-Kaczmarska, A. Risk factors and dynamics of weight gain in patients after liver transplantation. Ann. Transpl. 2009, 14, 45-50.

4. Leonard, J.; Leonard, J.; Heimbach, J.K.; Malinchoc, M.; Watt, K.; Charlton, M. The impact of obesity on long-TERM outcomes in liver trans-plant recipients-Results of the NIDDK Liver Transplant Database. Am. J. Transp. 2008, 8, 667-672. [CrossRef] [PubMed]

5. Wong, R.J.; Aguilar, M.; Cheung, R.; Perumpail, R.B.; Harrison, S.A.; Younossi, Z.M.; Ahmed, A. Nonalcoholic steatohepatitis is the second leading etiology of liver disease among adults awaiting liver transplantation in the United States. Gastroenterology 2015, 148, 547-555. [CrossRef]

6. Charlton, M.R.; Burns, J.M.; Pedersen, R.A.; Watt, K.D.; Heimbach, J.K.; Dierkhising, R.A. Frequency and out-comes of liver transplantation for nonalcoholic steato-hepatitis in the United States. Gastroenterology 2011, 141, 1249-1253. [CrossRef]

7. Bhati, C.; Idowu, M.O.; Sanyal, A.J.; Rivera, M.; Driscoll, C.; Stravitz, R.T.; Kohli, D.R.; Matherly, S.; Puri, P.; Gilles, H.C.; et al. Long-term Outcomes in Patients Undergoing Liver Transplantation for Nonalcoholic Steatohepatitis-Related Cirrhosis. Transplantation 2017, 101, 1867-1874. [CrossRef]

8. Kappus, M.; Abdelmalek, M. De Novo and Recurrence of Nonalcoholic Steatohepatitis After Liver Transplantation. Clin. Liver Dis. 2017, 21, 321-335. [CrossRef]

9. Anastácio, L.R.; Lima, A.S.; Toulson, D.C. Metabolic syndrome and its components after liver transplantation: Incidence, prevalence, risk factors, and implications. Clin Nutr. 2010, 29, 175-179. [CrossRef]

10. Schacke, H.; Docke, W.D.; Asadullah, K. Mechanisms involved in the side effects of glucocorticoids. Pharmacol. Ther. 2002, 96, 23-43. [CrossRef]

11. Watt, K.D. Metabolic syndrome: Is immunosuppression to blame? Liver Transpl. 2011, 17, 38-42. [CrossRef] [PubMed]

12. Curtis, J.J. Hypertensinogenic mechanism of the calcineurin inhibitors. Curr. Hypertens. Rep. 2002, 4, 377-380. [CrossRef] [PubMed]

13. Fernandez, L.A.; Lehmann, R.; Luzi, L.; Battezzati, A.; Angelico, M.C.; Ricordi, C. The effects of maintenance doses of FK506 versus cyclosporin A on glucose and lipid metabolism after orthotopic liver transplantation. Transplantation 1999, 68, 1532-1541. [CrossRef] [PubMed]

14. Zimmermann, A.; Zobeley, C.; Weber, M.M.; Lang, H.; Galle, P.R.; Zimmermann, T. Changes in lipid and carbohydrate metabolism under mTOR- and calcineurin-based immunosuppressive regimen in adult patients after liver transplantation. Eur. J. Intern. Med. 2016, 29, 104-109. [CrossRef] [PubMed]

15. Perez, L.V.; Alvarez, J.M.; Gonzalez, A.P.; Delgado, J.B.; Rodero, G.C.; Rivas, E.F.; Barrera Baena, P.; De la Mata Garcia, M. Prevalence and Predictors of Metabolic Syndrome After Liver Transplantation. Transpl. Proc. 2016, 48, 2519-2524. [CrossRef]

16. Satapathy, S.K.; Charlton, M.R. Posttransplant metabolic syndrome: New evidence of an epidemic and recommendations for management. Liver Transpl. 2011, 17, 1-6. [CrossRef]

17. Tan, H.L.; Lim, K.B.; Iyer, S.G.; Chang, S.K.; Madhavan, K.; Kow, A.W. Metabolic syndrome after a liver transplantation in an Asian population. HPB 2015, 17, 713-722. [CrossRef]

18. Anastacio, L.R.; Ferreira, L.G.; Ribeiro, H.; Lima, A.S.; Garcia Vilela, E.; Correira, M.I. Body Composition and Overweight of Liver Transplant Recipients. Transplantation 2011, 92, 947-951. [CrossRef]

19. Richards, J.; Gunson, B.; Johnson, J.; Neuberger, J. Weight gain and obesity after liver transplantation. Transpl. Int. 2005, 18, 461-466. [CrossRef]

20. Diwan, T.S.; Rice, T.C.; Heimbach, J.K.; Schauer, D.P. Liver Transplantation and Bariatric Surgery: Timing and Outcomes. Liver Transpl. 2018, 24, 1280-1287. [CrossRef]

21. Bianchi, G.; Marchesini, C.; Mazzocchi, R.; Pinna, A.D.; Zoli, M. Metabolic syndrome in liver transplantation: Relation to etiology and immunosuppression. Liver Transpl. 2008, 14, 1648-1654. [CrossRef] [PubMed] 
22. Sprinzl, M.F.; Weinmann, A.; Lohse, N.; Tönissen, H.; Koch, S.; Schattenberg, J.; Maria, H.L.; Tim, Z.; Peter, R.G.; Torsten, H.; et al. Metabolic syndrome and its association with fatty liver disease after orthotopic liver transplantation. Transpl. Int. 2013, 26, 67-74. [CrossRef] [PubMed]

23. Courivaud, C.; Kazory, A.; Simula-Faivre, D.; Chalopin, J.M.; Ducloux, D. Metabolic syndrome and atherosclerotic events in renal transplant recipients. Transplantation 2007, 83, 1577-1581. [CrossRef] [PubMed]

24. Canzanello, V.J.; Textor, S.C.; Taler, S.J.; Schwartz, L.L.; Porayko, M.K.; Wiesner, R.H.; Krom, R.A. Late hypertension after liver transplantation: A comparison of cyclosporine and tacrolimus (FK 506). Liver Transpl. Surg. 1998, 4, 328-334. [CrossRef] [PubMed]

25. Jindal, R.M.; Sidner, R.A.; Hughes, D.; Pescovitz, M.D.; Leapman, S.B.; Milgrom, M.L.; Lumeng, L.; Filo, R.S. Metabolic problems in recipients of liver transplants. Clin. Transpl. 1996, 10, 213-217.

(C) 2019 by the authors. Licensee MDPI, Basel, Switzerland. This article is an open access article distributed under the terms and conditions of the Creative Commons Attribution (CC BY) license (http://creativecommons.org/licenses/by/4.0/). 